\title{
MIKLÓS JANCSÓ'S HISTORICAL CINEMATIC SPECTACLES AND MOVING PICTORIAL FIGURATIONS IN A HUNGARIAN LANDSCAPE A STUDY AND A PHENOMENOLOGICAL PERSPECTIVE ON JANCSÓ'S FILMS OF 1960S AND 1970S
}

\author{
JARMO VALKOLA \\ Associate Professor of Film History and Theory \\ Baltic Film, Media, Arts and Communication School \\ jarmo.valkola@gmail.com
}

\begin{abstract}
In the following article, I examine the originality of Hungarian director Miklós Jancsó's (1921-2014) filmmaking practice. Jancsó appears as a unique representative of European filmmaking tradition who was motivated by a specific commitment to develop and increase the function of cinematic form, the effectiveness of images and sounds and performances of the actors which aesthetically formulate, translate and change the effects of Hungarian cinema to higher qualities and dimensions of art and spectacle. The significance of the filmic form comes forward, and the camera-based organisation of it increases the intensity of narration. Jancsó's use of folk rituals adds a strong sense of pictoriality to the overall narrative structure, because his emphasis lies in the physicality of different appearances inside the frame. In his own stylistic way, Jancsó processes these various formations executed by the performers in a style in which all the elementary forces - whether physical, pictorial, psychological, or aesthetic - work in conjoint with one another. In this regard, Miklós Jancsó's cinematic spectacles are symbolical fantasies enriched by phenomenological realism.
\end{abstract}

Keywords: Miklós Jancsó. Hungarian cinema, audio-visual spectacle, formalism, style, performance aesthetics, history, myths

Hungarian director Miklós Jancsó (1921-2014) became universally known as a filmmaker at the 1966 Cannes film festival, when his film The Round-Up (Szegénylegények, 1966) was screened and met with an enthusiastic reception. At the same time, it was clear that a new and very specific talent for the international cinematic scene was born. The film is set on a vast Hungarian plain, puszta, the year is 1868, and Austro-Hungarian troops are trying to break the unity of Hungarian partisans by using interrogations, torture and killings.

In some other director's hands, The Round-Up could be just one way of dealing with a nation's history, but in Jancsó's hands this is something deeper: a study 
of milieu, rituals, and history of a certain culture proceeding on a non-illusionist level of living.

At the same time, The Round- $U p$ creates a vision of a timeless period, which works on a symbolic level since it deals with historical myths and basic living conditions. The film is structured around epic dimensions dealing with expanded length of shots and images, which features a game of rituals with no real pity.

The identity of people is measured and controlled by selfish interests. Even the treatment of objects has these meanings dictated by selfishness. This all creates a cold vision but maybe it also conveys an increased gravity of the situation, and maybe it is also a geometrical presentation of evil and fear. Jancsó's stylistic bravura reaches its culmination points with the overall design connected with filmic devices, the grandiose camera-pans, the effective close-ups, the rhythmic editing, which has a kind of musical quality (in a film that has no music), etc.

Generally, in Miklós Jancsó's films of the 1960s and 1970s, in films such as The Red and the White (Csillagosok katonák, 1967), Silence and Cry (Csend és kiáltás, 1968), The Confrontation (Fényes szelek, 1969), Agnus Dei (Égi bárány, 1970), Red Psalm, (Még kér a nép, 1972) and Electra, My Love (Szerelmem Elektra, 1974), the focus of the narrative form is not really concentrating on each individual camera movement of each section, but on the consequences of audio and visual relationships, and the arranged movements and relations affecting the space. The audio-visual effects produced by actors and camera movements are concerned with the spatial qualities of narration. This features intensive shooting and editing "through the camera movements", as actually the form of narrative is avoiding editing in the classical sense. The implications of entering the space of the film mean that the camerawork activates the space and the landscape. ${ }^{1}$

\section{Exploring the space}

In this sense, the landscape of a Jancsó-film of that period forms an open narrative space with a field or range of a sphere in which its relations and viewpoints are equally distant from the centre of action. It creates an effect of narrative and spatial logic, which is brought into existence from the inside out, since the camera's geometric arrangements create a circular pattern of narration in which its internal logic is the decisive force of the viewer's experience. Both space and time work as indicators of actions of the camera and events that are chronologically represented.

These include the concentration on framing the shots and on the movements of the performers, controlled by the actively mobile camerawork, which creates changes between still-moments and walking. Subsequent variations of these strivings appear later in the narrative, and the exploring of the space is enlarged into new areas, which also transforms the spectator's perception. The temporal 
extensions of Jancsó's approach are seen in the beginning, and we can sense the uniqueness of the style through the conveyed audio-visual information. The spectator notices the categorical uniqueness of Jancsó's filmmaking practice, in which the viewer's attention is concentrated according to the movements of the performers, their places inside the frame, and the camera's multiple ${ }^{2}$ activations. The gaze of the spectator follows the movements and appreciates the spatial changes connected to it. In certain scenes, the directions of the camera movements guide the viewer's eyes to the edges of the screen. Other movements with bisecting intervals act as lines directing the spectator's look to notice the different parts of the screen.

Through his filmic stylization, Jancsó follows the classic search for perfection in terms of pictorial sensibility and readiness to control the visions. These visions of the environment, nature and other phenomena are composed entities, carefully arranged pictorial views and expressions, which are seeking to unfold human experience into an organised existence. A search for general perfection can be found among these filmic samples, which provide an illustration for the particularity of matters equipped with an encompassing range of ideas, and focusing on the images and sounds embracing the edges of imagination. One can benefit from the approach and exercise by following the arrangement of views and evocative perspectives that attempts to capture a certain pattern of representation that has shaped the director's vision.

\section{A wide discourse}

The present approach is, therefore, dedicated to an understanding of Miklós Jancsó's cinematic oeuvre as a concept, and a specific movement among the arts. It appears especially in cinema as a practice of filmmaking, and as a dialogue between art, aesthetics and philosophy. The perception of audio-visual narration is a question of seeing these connections in relation to the history of art. These are the main points addressed in the study. Jancsó's filmic work is seen as an essential part of developments, and as a modern way of dealing with the artistic practices of our time. The development of audio-visual communication forms a partly theoretical and partly practical background to these endowments.

At the same time, as this development is seen as a connection between the earlier and contemporary dimensions of art, it is seen also as a sign uniting traditions and modernism. The perspective tries to avoid simple solutions and promulgate an understanding of further levels of comprehension and interpretation connected with possible reorientations of history, art, cinema and aesthetics. I would like to locate my study and discourse within several fields; namely, film studies, history, aesthetics, performance, representation, phenomenology and cognitive studies. ${ }^{3}$ 
In each case, I want to describe and interpret especially the formal features of Jancsó's films, using the link to significant historical periods, and their interpretation through filmic devices. I intend to develop an analysis that starts from these matters and examines Jancsó's filmmaking practices in order to understand their influence on our perception of the past and present issues, whether they are real or imaginary.

\section{Controlled narrative formations}

In Jancso's cinema, it is noticeable that diverse media connections inside the narrative can possess a specific capacity to serve as a means of communication, to transfer and deliver, for instance, moments of still-life or pictorial stillness, which can come across and mediate images and pictures consisting of predominantly non-moving characters or inanimate objects. As these elements appear in the narrative, pictorialism also renews itself, foreboding future narrative developments. Of course, these pictorial reflections can also mediate movement, implying no more than the idea of the changed positions of the characters or, as in the case of Miklós Jancsó, Theo Angelopoulos, Andrei Tarkovsky, and Béla Tarr, showing a series of actions taken by a group to achieve an impression of joined movement on the scale of narrative, repeated actions. These are specifications of audio-visual communication, detailed and precise presentations of cinematic outcomes in the modern language of cinema. ${ }^{4}$ They consist of architectural forms, filmic inventions, and single items of this selective representation. They can bring tenseness or density to a single scene or image adopted for the further purpose of the narrative.

Miklós Jancsó managed to make over 40 short films before his Cantata (Oldás és kötés, 1963) started the magnificent period of Hungarian cinema in the 1960s. This film is structured around elements that could be from an Antonioni-film: crisis of the intellectuals, a break-through from the burden of former of the older generations, and a search that becomes a voyage. The main character of the narrative is a surgeon, and the narrative features a sequence in which there is a penetration into the human heart. After this the "Jancsó scenery" unleashes, featuring the Hungarian puszta with its operatic dimensions.

Jancsó's style is one of the most original among modern cinema. Usually, his films consist of 10-minute shots, which have a resemblance of a collective ballet, handling the relationships between oppressors and the oppressed. Masterful technique shows not only its technical brilliance but is a natural consequence of matters that are based on Jancsó's historical vision.

In my mind, these relations form a unique corpus and, in some sense, even a principal substance of the narrative whole. As an individual designer, Miklós 
Jancsó has the possibility of controlling the narrative actions. He has the ability to arrange or produce changes inside the narrative chain. This can emerge as the unfolding of events, which can be arranged and marked by present actions, or have the nature of symbolically implying further indications of represented actions in the Jancsó-films of the 1960s and 70s. The topics of these films include peasant uprising, Greek mythology, mediaeval accounts and Roman antiquity, among others and more contemporary references. It is noticeable that, for instance, the year 1919 is represented in three films; namely, The Red and the White, Silence and Cry and Agnus Dei, but each time from different perspective. The Red and the White represents how Hungarian volunteers are fighting on the side of the Bolsheviks in the Russian Civil War, while Silence and Cry depicts the aftermath of Hungary's short-lived Communist government of that period and Agnus Dei illustrates the last days of the same regime.

\section{Historical underlining}

The historical touch of Jancsó follows Marc Ferro's idea that cinema is "a source and an agent of history", since a single framing of a film can contain the entire memory, both for what it shows (its past or current image) and for what it suggests (its missing image) (Ferro 1988: 14). According to this reference, cinematic ideas and spaces they depict, not only refer to the past, but also to the present and future. They shape and underpin our senses and our perception in the sense that they are our source of inspiration. ${ }^{5}$ As understood here, many Jancsó's films are also collective memoryscapes that go back to a more or less idealised past, as well as individual mindscapes that offer new meaning for traces of the past, thereby creating an imaginary cinematic reality that complements the historical one and, in some cases, even foresees its future developments. No matter how much time has passed since the disappearance of a given memory, the film can show it, and although it may be covered with a feeling of nostalgia or melancholy, it still stimulates the filmmaker's creativity, whether by embracing the usual parameters of historical discourse, or simply depicting the awareness about the passage of time. The main advantage of Jancsó's approach is based on intersubjectivity, the ability to create a shared experience, in which Jancsó conveys his metafilmic strategy in building a cinematic expression that includes his own vision and perception of history, open for a wider audience. ${ }^{6}$

Electra, My Love is based on László Gyurkó's play which was, in turn, based on the myth of Elektra. The film is set 15 years after the murder of King Agamemnon. Elektra (Mari Töröcsik) still believes that her brother Orestes will return to kill the tyrant Aegisthos (Jószef Madaras). Aegisthos orders his people to celebrate and announces the death of Orestes. In the narrative, a messenger (György 
Cserhalmi) arrives with news of the death of Orestes and Elektra kills him. Resurrected, he turns out to be Orestes and, together with Elektra, provides the focal point for the people's revolt against tyranny. Their role is to die and be reborn like the phoenix, the firebird and symbol of revolution. There are only 12 shots, namely long takes in the film, cinematographed by János Kende, and balletic movements emphasise the arrangement of narration.

The whole comprises a magical tale, an electrified, ancient drama of Greek mythology. The very distinctive features of Electra, My Love display a feminine-centred narrative; it's structure is energetic, focused on themes of truth, justice and freedom. Mari Töröcsik's performance controls the narration with a sense of specific sensual presence. Electra, My Love goes even beyond this, on to the basics of primal symbolism, expressing an uncompromising female challenge against her oppressors. Song and dance are her weapons in this struggle, and huge audio-visual fiesta, which clearly demonstrates the power and elegance of movement in Jancsó's choreographed entity.

On a large scale, these movements of the narrative can be capable of referring to historical states or conditions of cinematic language. By this I mean that it is a question of working out and developing the evolution of cinema and virtual culture since, through the development of audio-visual communication, we have arrived at a new stance and another kind of intellectual and emotional readiness, connected with late modernism, through which we can find new ways to connect different forms of media, causing interactions inside the cinematic canon and forming a display of noteworthy events.

As a mode of filmmaking practice and style and as a variation of aesthetic, technological and other qualities of representation, Jancsó's filmic style is both an independent sign of stylisation and a unit of the language of cinema, a part of the total structure and an arrangement of the tones, schemes and expressions of the filmic universe. In Jancsó, its value comes from the relative importance and magnitude of its possession of control and influence to act as an audio-visual centre and force implying physical, mental (or even spiritual) abilities, or a quality of characteristics that enables its workings inside the narrative chain to produce imaginable meanings and connections.

In this regard, Jancsó's style works as a stronghold of the means of communication associated with various forms of art: photography (the process of producing images on a sensitised surface or virtually); cinema (the process of producing moving images through audio-visual display-from the Greek kinëma, motion); painting (the process of representing lines and colours on a surface by applying the substance of pigments); and architecture (the art or science of designing and building structures).

As this makes clear, Jancsó's cinematic style combines the spatial (extents in which objects and events occur) and temporal (time-related) dimensions of cine- 
ma in bringing together the formal (and mental) act of the still-life representation and visual presence of proposals for action to adjourn and enlighten the scope of narrative. This works as a combination and coexistence of these diverse forms of presenting images (and sounds) to serve and act as signs and symbols in certain phases of narrative to produce an especially marked influence or effect on the sense and mind of the spectator. This can appear as a form or impression of the depiction of an image or a scene evoking a sense of historical or other realities processed under the skin of the narrative; or as a mental continuity of events occurring in the narrative chain. As a conclusion to these modulations on Miklós Jancsó, the tension between the quick instances of motion and movement and the sudden, almost immobile action is brought into existence.

\section{Imaginative arrangements and painterly visions}

Jancsó has often been blamed of making abstract films, although he is a director that clearly handles historical situations with a concrete vision. By avoiding personal psychology, Jancsó actually creates more realistic drama than many other filmmakers, since he studies only matters that can be handled through cinematic means. His narratives are depicting a topic that is the greatest one, namely history, which, in many sense, contains the most important issues of life.

Jancsó's symbolic parables are concrete documents of the mythological past of Hungary. Many of his films have a connection with the Civil War. The Red and White happens in Soviet Union and resembles Russian films of the 1930s. Silence and Cry and Agnus Dei are situated in Hungary. The latter creates a vision concerning collective happenings and s rise of fascism. Jancsó has stated: "Irrationalism rises everywhere, and its forms include religion, various folk-movements and right-wing anarchism. That's why I'm on the roots of these phenomena in Agnus Dei."

The Confrontation is nearer to modern age. It happens in the year 1947, when a group of young communists try to turn the heads of the students of theology, first through singing and dancing. Later on, these features are aligned with ritualistic violence. The film is a fully controlled combination of preplanning and spontaneity. Jancsó's geometrically sharp direction controls the actors and ends up into a collaborative expression of inner and outer forces. The power of expression lies in the unity of the topic and method, since they reflect each other. A 4-minute plan-sequence opens the narrative with Andrea Drahota, Lajos Balázsovits, András Kozák, Kati Kovács and Benedek Tóth in the main roles, cinematographed by Tamás Slomló and edited by Zoltán Farkas. The narrative is geared around circle as the main visual design of affairs with ornamental decorative forms and rituals. Jancsó's screen is phenomenologically open to all senses featuring em- 
bodied experience, foreground and background relations of characters in a milieu, evoked by the virtual time-space of moving images. Jancsó's description of happenings is resonant with impressive and emotional responses.? "Rendering almost every scene in a single shot effectively denies us the spatial ubiquity of a more editing-centered style. Within the scene, this narration refuses to show us anything that is not within the ken of a traveling camera; no instantaneous changes of angle, no crosscutting. Yet this restriction is not motivated by the limits on a character's knowledge."

In these discrete and self-contained formations, the cinema of Miklós Jancsó configures itself and exposes its connections as an interaction between an artwork and the audience. We can experience ourselves in time, phenomenologically bracket out the objective reality and rely more on intentions to figure out these proponents of spatial and temporal impressions through which cinematic spaces were formed and technological transitions initiated. ${ }^{8}$ My claim is that the audio-visual outcomes of Jancsó's films feature an original persistency of vision that has its clearest, although in another sense different, cousins in modern cinema, especially in the works of directors such as Michelangelo Antonioni, Peter Greenaway, Andrei Tarkovsky, Béla Tarr, and Theo Angelopoulos.

Jancsó's cinema can be understood as a tension between a mode of vision at distance where objects are presented as forms and figures in space, and a mode of vision that appeals to tactile connections on the surface-plane of the image. Jancsó's filmic images invite a "look" that circles on the surface-plane of the image for some time before connecting to the details. The durational dimension of the spectator's perception comes about because of the "thickness" of the images, which requires that the observer delves into the image, and brings his or her resources of memory and imagination into play to fulfil the message of the image. ${ }^{9}$ In this regard, we might be somewhere in the middle of the images and sounds of an individual work to experience and possibly contemplate on the matters of form and content that function within this interactive system of implicit and explicit dichotomies. As Richard Eldridge exemplifies:

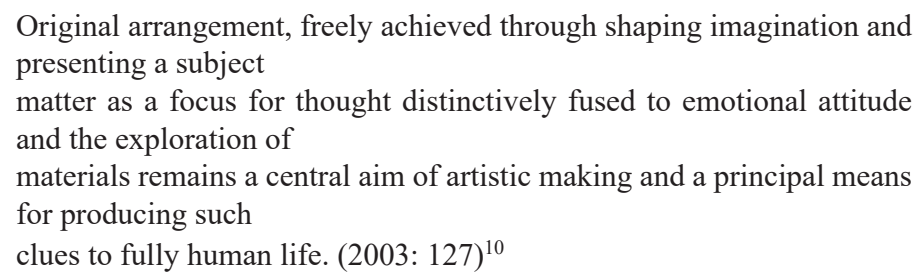

Miklós Jancsó's cinematic discourse inscribes pictorial codes of developing the image in connection with a specific durational power as an emblem of self-definition through its very constituent elements. Simply by catching these visions, 
Jancsó can create tension in the scenes by providing them with specific intervals designed to support the architectural nature of the narration.

Jancsó's painterly visions are connected with the film's ability to hold and concentrate on certain aspects of narrative, including the pictorial stillness of representation, and its complex outcomes. By looking at things in this way, Jancsó activates the spectator's understanding of the happenings, creating a tension between the history of Hungary and its present state of life. The sites of the narration underline the places in which something usually happens in the period of history, causing changes in the narrative structure of the films.

While some of his films evolve around modernist perspectives, there is the double-layering of history that touches the present and brings forth new aspects. They all raise the more or less recurrent questions around the historicity of Jancsó's approach. The question of our relationship and understanding of the past is more than crucially related to the content of the images. Our initial comparison of Jancsó's filmic work can be now specified. On a broader level, it seems that Jancsó's way of dealing with historical issues occurs often without a clear intention, since he does not seem to be very interested in explaining the historical background of happenings.

Jancsó's filmmaking practice is a vision that deals with a view of film as an autonomous, pure medium, and it is grounded in the notion that cinema has grown both independently and together with other media such as photography, painting and architecture. It gives him the possibility to elaborate and explore the different layers of audio-visual traditions as a mode of disclosure of spatial and temporal ideas. These principles are crucial insofar as they are his operative guidelines expanded in space, by which an individual film is made to integrate pictorial, environmental views, and by which the modern forces of narration are balanced. This expansion plays an important role in the creation of the audio-visual qualities of narration.

Jancsó produces a timely and organised historical narrative with the sublime effect of the landscape represented fully in films such as Electra, My Love, Red Psalm and The Confrontation.

\section{Panorama of people and objects}

This formation of cinematic and natural forces entails an understanding of the combination of pictorial and aural possibilities depending on a vision of Hungarian film culture, transmitting a panorama of objects and situations that is precisely there, and made entirely visible for the viewer. It is a creation in the most traditional sense of the word. The affective charge for a person committed to the comprehension of others and the experience of trauma are, of course, elements of difference to the person who has really experienced them and to the spectator 
but, in Jancsó's hands, these signs in the narrative structure of films such as Red and White, Electra, My Love, The Confrontation, and Red Psalm can produce an effect of inseparability of narrative and its temporal dimensions.

They work side by side in the articulatory practice of Jancsó's cinematic methods expressing effectively and distinctively the shades of meanings consisting of these filmic segments. While the first section of Electra, My Love is more observational, concentrating on the presentation of characters, their "history", and their milieu, the second half is more "social" (even political), and ambiguous both in its content and style. The habits and mannerisms of characters have merely been exposed but they remain partly unexplained, since, after all, we know very little about their lives.

Agnus Dei, Red Psalm, and Electra, My Love are tentative, and reflexive films based on historical encounters that Jancsó creates in front of the camera. Their most valuable lesson is certainly in their pictorial treatment of the bodily movements on the screen. Their unusual organisational models and their pictorially centred and oriented logic, and range of thematically organised subject matters serve as a measure of their ambition. In Jancsó's films, some images look like frescos, canvases filled with temporal duration. After a brief moment of the characters' appearance, they are already on the move, and their body movements are about the continual effort to do so and meet the forthcoming expectation of motion.

Consequently, their movements imply changes in the condition of their environment. In the sense of spectatorship, they are our anchors in time and space. They are located in the landscape and, at the same time, in our mental mindscape. As the characters move rapidly across the screen, the contours of their performance develop, and with Jancsó, this process is constructed as an exceptional choreography of human and camera movements. Entering into their specific state of appearance, the motion of the camera expresses their continuous body movements. We perceive their actions as a sequence of phases. The image of their presence turns into an audio-visual representation of characters and their movements.

The films are statements of the cineaste's aspirations featuring a personal memory-scape. Considering that characters in the discourse have no absolute final meaning, their combined presence in the same work allows a filmmaker to develop a creative historical discourse of his story without ever losing the sense of place. In cinematic context, it means a relation to the production of image-memories through montage, narration and mise-en-scène. Therefore, Jancsó is concerned with the transference of conscious and unconscious elements into a narrative that works as an expressive reflection of the personal and national history in a situation in which the deployment of the past actions is spread out to various memory levels in order ${ }^{11}$ to connect memory and history. From this perspective, all this functions as a way to realise how psychic and personal ambitions can set out filmmaking practice that covers the elementary forms of existence. 
This emphasises a look that stays on the surface of the image for some time in order to realise where to focus next. This accounts for the pictorial quality of representing the image as a field and the source of deciphering contours between stasis and movement, surface and depth. All this forms a cinematic milieu that results from these mutual interactions with painterly and atmospheric renderings in a landscape of emotions whose elements work as interfaces of dimensions in space and time. It is precisely in these terms that we can best associate the pictorial turn of image in Hungarian film culture, the mutation from previous paradigms to a new sensitivity of pictorial forms of expression.

The pictorial development of film is crucial here. The landscape or the image of the landscape works with a certain "Hungarian" iconography in Jancsó's films. These views are stylised, containing a real sense of echoes of the Hungarian past. All the views are tightly tied to audio-visual representation. Our reading of his images often happens horizontally. This horizontality is crucial, since in Jancsó's films of the 1960s and 1970s, the landscape opens with a general view, which presents gestures of movement, and then the camera lingers around these gestations locating the people and their positions in the frame.

Human gestures form an especially rich array of possibilities for Jancsó because of their functionality and meaning as signs, which convey intentions, emotional states, and commands. Symbolical gestures are, in this following, derived from functional and signalled behaviour in recording small or large changes of position, looks, gestures and motion, which indicate vitally important intentions.

The precision of the formal qualities of the cinematic composition is needed to communicate the audio-visual characteristics of a scene. In Jancsó's cinema, the compositional force is born out of the integrated movements that manifest the necessary repetitive aspects of a scene to work out pictorial controversy. This is done through perceptual factors; the complexity of the movements, the orderly grouping of the performers, the distinction of figures and ground, and the use of light and perspective to design the spatial values of the narrative. The depth of the visual field is punctuated by the elements of the picture. In these moments, the horizontal reading of the images invests the narrative with a painterly effect of moving images in motion. Depth significantly extends the pictorial affectation of single images referring explicitly to the very original nature of Jancsó's filmmaking practice.

\section{Strategies of camera-based observation}

In films such as Red Psalm, Electra, My Love and The Red and White, landscape is used as a means of exploring its contours through camera movements. This is focused through an introduction to the themes and subject matters of the narrative, the strategies of camera-based narration, the pictorial use of relationships 
between characters and landscape, and by activating links between on-screen and off-screen happenings. All this makes possible the representation of the filmworld.

In Jancsó's films, there is a correspondence between performer and environment that operates through the staging of natural settings. He adopts strategies of perceptual interrogation associated with the presentation of pictorial elements, viewpoints, and camera movements. He sets the stage for the essential information of "social" knowledge concerned with Hungarian society, and Hungarian film culture, and value-system linked to forms of presenting the camera-based observation of social life.

His image-sequences (plan-sequences) reinforce ideas of psychological, physical, material, and social existence, based on character-identities explored throughout each film. These connections are associated with other verified narrative dimensions proposed by each film. The audio-visual representation of these visions can serve as the materialisation of on-screen and off-screen views.

Through his films Jancsó is disclosing the role of perception in constructing the traces of historical accounts of the past on the basis of the view that a thing related to the past is never simply external to the perceiver, as these signs can create and unfold a web of internal relationships between the levels of narration. Jancsó's filmic productions are the signs of historical perception representing his way of perceiving the world, and, at the same time, they make possible the subjective involvement of the viewer. Occasionally, the subjective view can increasingly grow and give space to a more objectified view of perception. This phenomenon is not a function of the viewer or Jancsó alone, but an intention to which they are connected, constructing the overall audio-visual dialogue.

His scripting of space happens partly through his meditative look on characters and their environment, and partly because of his specific understanding of the pictorial possibilities of audio-visual representation. It forms a controlled endeavour through which Hungarian film culture is explored within special ritualistic, formalistic, and environmental parameters. Its significance is born out of conspicuously investing the narrative with a method of seeing and investigating the filmic world of appearances that phenomenologically relate to one another through Jancsó's sophisticated modes of filmmaking practice.

\section{Aesthetics and space: A choreography of matters}

Miklós Jancsó's Red Psalm is pictorially and cognitively an exceptionally interesting example of art based on historical events, as the storyline follows a series of revolutionary peasant uprisings in Hungary between 1890 and 1910. The Hungarian title Még kér a nép is the title of a poem by Sándor Petőfi meaning "the 
people still demand", referring to the theme of the film. The scriptwriter of the film, Gyula Hernádi found a notebook of "Socialist psalms", and he and Jancsó were heavily influenced by Deső Nagy, a historian, who emphasised the meaning of popular folklore as the inspiration for the uprisings. Yvette Biro, credited as dramaturge, helped transform the ideas into dramatic actions and characters.

The actual performances in the film are imaginary, and many of the incidents and happenings inside the narrative were improvised during the shooting of the film. The setting of the film is the Hungarian plain with a river, a church, some farm buildings and a railway line. The film begins with a peaceful image of a woman's hand holding a dove and the image is accompanied by the tinkling of bells, and the music of the "Marseillaise". The scene stretches out to show a group of male and female peasants, horses and soldiers in uniform. The local bailiff steps in, and the peasants sing, dance and walk. The bailiff tells the peasants that he wants to talk with them and the latter demand rights for the people.

One of them reads Friedrich Engels' letter commenting on the political situation in Hungary in the late 1890s. The bailiff withholds sacks of grain from them, and a blond woman (Andrea Drahota) tries to link the separate groups of villagers. The soldiers are approached by a group of women who take their rifles and throw them on the ground. They then confront the bailiff. The peasants dance around to the music of Carmagnole. A folk-violinist quietens the mood, and a few officer cadets hover around the folk-dance group curiously or thoughtfully.

Jancsó's film is another example of a study of rituals, milieu and the history of a certain culture. Again, Jancsó creates a vision of a timelessness, which happens through symbolic forces dealing with a phenomenologically created atmosphere that combines historical references with a specific view of struggle. The film is developed around epic dimensions offering an expanded length of shots and images, and an expanded game of rituals. The identity of people is measured and controlled by selfish interests. Even the treatment of objects has meanings dictated by selfishness. All this creates a cold vision but it maybe also conveys an increased gravity of the situation, and maybe it is also a geometrical presentation of evil and fear. In earlier Jancsó-films such as The Round-Up and The Red and White, women are seen mainly as victims of male violence, but from The Confrontation onwards, women begin to take more active roles in resisting the opposition and attempting to defeat it (Petrie 1998: 26). ${ }^{12}$ In The Round-Up, the occupying Austrians promise a peasant that he can escape execution if he can find a partisan who has killed many people. Before suffering torture or execution, victims must march in single file, form circles, strip or lie down, or undergo absurd ceremonies which merely display their subjection to the will of authority. Jancsó belonged to a generation appalled by the revelation of wartime atrocities, and the Nazi death camps. In his films, Jancsó suggested that power was exercised through public humiliation, and the total control of the victim's body (2003: 465). ${ }^{13}$ Jancsó's sty- 
listic bravura reaches its culmination point with the overall design connected with all Jancsó's cinematic devices, the grandiose camera-pans, the effective closeups, and the rhythmic editing which has a kind of musical quality.

Jancsó creates an impression of space with a vision that is not only pure choreography and external artistic skill, but also works as a presentation of national cinematic culture, and in which, for example, the close-ups are expressions of feelings and emotions, clues to what the performers are actually thinking about usually something that is beyond words.

The style of Jancsó's films is geared to a collective struggle. The moving camera makes no separation of leaders, and Red Psalm develops an essentially literary text by the means of physical movement, and the film's minimally terse dialogue suggests actions without specifying historical trends and moments. Characters are mainly not individualised, but presented mostly as anonymous performers. Almost all villagers are young, and the practically total absence of old people seems to function as part of the film's stylisation.

Jancsó's style is often an abstract and increasingly complex combination of camerawork, dialogue, sound, colour and music. Red Psalm shows his characteristic style as most expressive and powerful. The direction interweaves different dimensions of space, movement and change. Most unusual is the walking choreography with its changing body movements and rhythms. There is also a strong pictorialist dimension within the landscape images. They are often revealed gradually, and the camera movements become a focus of attention with their own kinetic dynamism. They are calligraphic, so the camera lens seems to move across the scene as a pen moves across a piece of paper. There is rarely any one centre of visual interest that is followed throughout the shot.

Usually, the camerawork is a combination of zooming and tracking, and shifting from one individual to another, and from one group to another as they confront one another and intermingle throughout the narrative. The camera does not stay with one activity or character for very long, and often incorporates several centres of interest within the frame. From this constant succession of actions and movements emerges a pattern that sets up the play of opposing forces, and qualifies the nature of on-going confrontation between different groups. The lack of interest in following certain characters and performers throughout the scenes, and the avoidance of following a conventional plot structure give the film an episodic and abstract nature in which the focus shifts changes without warning from one series of actions to another (Petrie 1998: 30).

Jancsó tried to avoid normal continuity, and instead of that created a kind of different continuity with a focus on certain themes and structures rather than following characters and their actions. Visual and rhythmic delight is created mostly through the moving camera. The compositional values of the narrative are very high and, for instance, in the scene with the peasants' massacre by the soldiers, 
the camera watches everything from a high angle and in a long shot. This creates a majestic composition with painterly dimensions. to lengthen space-time.

Though Jancsó's cinematic spectacles emphasise long shot arrangements, he also uses straight and abrupt cuts, usually from a long shot to an initially complacent close-up, introducing another scene. He does not us conventional establishing shots in his oeuvre. If the overall momentum of affairs is less strong, the close-ups might break the flow and the mood of narration. The soundtrack is meticulously wrought especially when overlaid sounds add aural space to visual space, the sparse use of words enlarges the local actions to wider patterns of history and the music suggests moods and tensions inside the narrative.

In Red Psalm, as in Elektra, My Love some of the characters come in pairs, and many elements in the films are actually paired in one way or another. As well as pairs, there are triads and, in drama as in history, these relations change all the time during the course of the narrative. The cinematic forms are descriptive since the narrative events could have remained identical even if technical or other factors had created different outcomes. Generally, fiction writers shape the narrative to accommodate a character or a scene which they wish to take in at the same time as their descriptions respond to certain narrative requirements. In Jancsó's universe, the overall descriptive stance of his filmic display dominates the narrative, and vice versa.

The basic unit of film, the photographic shot, is a descriptive, pictorial structure, and in all of the arts, style serves description as conspicuously as it serves narration. In Red Psalm, the pictorial landscape becomes an arena like a theatrical space, which is created by a body of actors whose relations assert a visual and diegetic unity (Durgnat 2003: 120). ${ }^{14}$ The same logic applies to a conventional theatre when actors enter the space around them, or play scenes amidst the audience as well as on stage. There is a sense of spatial unity in Red Psalm, and it is there even though many changes of setting, breaks of action, and edits of time do appear.

In Jancsó's films, the general approach to découpage is mostly concerned with the cineaste's will to control the mise-en-scène, e.g. what happens in the image. In this sense, a single shot with all its changing patterns forms the basic compositional unit of the narrative. In the editing phase, Jancsó created the shot lengths according to his vast pictorial patterns and schemes of expectation. In the cognitive sense, the audience adopts subliminally these changes of shot development. The pace of the cutting is swift and full of different developmental lines, since it is expected to dominate and control the overlaid aspects of the material. According to his audio-visual pattern, the duration of the images and shots is developed in conjunction with the plotline revelations, achieving a specific formulaic quality. Generally, this means the way that the shots are joined together in an audio-visual manner. The causal lines of events happen alongside these shot developments, 
and when a new causal line is introduced, the cutting closes the previous one, or returns to it later This affectation is completed with the intricate play of spectator expectations. The visual logic of Jancsó's cinema is created by eyeline matches, connecting links with scenes and building the overall narrative context. Changes in the action lines are usually punctuated by the entry of the characters and their movements. This can sometimes include brief moments of character presence that can have effects on the overall continuation of a scene. In Hungarian cinema, these cognitive and phenomenological connections can achieve the state of artistic eloquence with its painterly affectations that evocate the floating reality of an Hungarian puszta film, and the affective presence of filmic figures and lines. As a consequence of this, a Jancsó film can be, at the same time, an observation of figures (performers) in a specific landscape, heightening its pictorial finesse and conceptual abstraction, and a depiction of the puszta as an open space for emphasising the complex presence of pictorial, perceptual vision, a frame-based audio-visual engagement with images and sounds. These compositional features are clearly expressive in Jancsó's films of the 1960s and 1970s.

The Jancsó-model of space is created through a compositional logic that exposes the placement of characters in their environment, evoking an atmosphere of austere connections exemplified in the purely pictorial and audio-visual patterns of the depicted world. In Jancsó's cinematic narrative, the space, the puszta, forms an open stylistically formed entity that operates as a visual arena of our understanding of the events. These formal actions invite the audience to participate in an open-ended spectacle of narrative construction. The filmic style searches for narrative logic, constituting of rules and activities that form an area of gradual awakening on the part of the audience that follows the narration, which conveys central thematic points of narration. Jancsó's outdoor staging relies on grandiose découpage and the depth and aperture effects characteristic of the director. In outdoor-planning, he insists on moving his characters side by side with one another. He then treats their common directional lines as an axis along which the shooting happens. The camera thus either faces the action or frames it from various directions.

In this respect, Jancsó anticipates the Greek director Theo Angelopoulos, another landscape artist. They both developed totally filmic settings as forms of extended theatre. ${ }^{15}$ In Red Psalm, Jancsó is able to combine richly realistic elements with a stylised choreography of movements and actions. The real surprise of all this is that the outcome is not totally unrealistic or artificial, but mostly a melange of different elements. Jancsó's use of folk rituals adds a strong sense of pictoriality to the overall narrative structure, because his emphasis lies in the physicality of different appearances inside the frame. In his own stylistic way, Jancsó processes these various formations executed by the performers in a style in which the elementary forces - whether physical, pictorial, psychological, or 
aesthetic - work in conjoint with one another. In this regard, Jancsó's films are symbolical fantasies enriched by phenomenological realism.

\section{Readdressing Hungarian film culture}

The Hungarian cineaste has the capacity to expand the language of cinema, registering achievements of exceptional quality and Jancsó's cinematic syntax consists of complex shot combinations, which can generate a variety of messages and meanings. Such constructions touch on the "mystique of cinema", creating a peculiar and original cinematic reality. His film phrases, constructed through fragmentation, tamper with reality by showing the total geography of a setting and spatial relationships. Jancsó exemplifies that the intensity of the audience's involvement depends on the filmmaker's arrangement of dramatic sequences. His films function on many perceptual levels, which are addressed according to the rules of performance. Generally, art films are expressive of national concerns, and characterised by the use of self-consciously artful techniques, which are designed to differentiate them from the merely entertaining popular cinema.

This strategy enables the art film to be viewed as part of national Hungarian film culture which is worthy of particular attention. The resulting inference is that in evaluating a work of art we should consider not only the formal properties, but also such elements as the philosophical ideas, the emotional expressiveness and the fidelity to the represented external reality. In the reception and evaluation of a work of art, we do not concentrate only on the appreciation of its formal properties, since we need to also discover cognitive dilemmas and moral endorsements. In Jancsó's films, the formal elements and other patterns of expression are referred to as choices, as when an artist contemplates and articulates his essential points he has an array of options. Creating an artwork involves the electing of forms that the artist finds useful, and which will function optimally in the final realisation. Accordingly, forms are formal choices and marked stylistic events when they are selected from a certain array of options. Forms are also selected and intended to perform certain functions.

Though the importance of form was made especially apparent by the tendency of modern art towards abstraction, significant form was a property said to be possessed by all artworks concerning past, present, and future. Significant form is comprised of the arrangement of lines, colours, shapes, volumes, vectors, and space. Art addresses the imagination of the audience as it was believed in Gestalt psychology, prompting the idea that the audience "fills" the artwork as an organised configuration of lines, colours, shapes, vectors and spaces. ${ }^{16}$ Another statement was that films renew our perceptions and other mental processes, as art is a sort of mental exercise. The spectator's relationship to the artwork becomes 
active, and the audience is involved on the levels of perception, emotion and cognition. possibilities from within the contours of audio-visual representation. Jancsó creates an impression of space with a vision that is not only pure choreography and external artistic skill, but works as a presentation of national cinematic culture, as well, and in which, for example, the close-ups are expressions of feelings and emotions, clues to something what the performer's area actually thinking about - usually something that is beyond words.

One conclusion can be drawn concerning Jancsó's films, and that is that there are no private acts, since whatever the people in his films are doing, they are responding or rebelling against the current social order. Not a single human being can avoid of taking part in the power struggle, either as a tool of a manipulator or as a victim of circumstances. Behind all this extremely original cinematic language, lies Jancsó's dream, which is a dream of human equality - this is his perspective, and a touchstone of his morality.

What is common to his filmic works is an attempt to bring forth the spacetime connections which emphasise human aspirations together with formal cinematic design and the presence of body movements in a vast arena of the milieu. Jancsó's "socio-historical cinema" articulates specific ideas and viewpoints concerned with past and present issues. We need various insights to understand this, and it is clear that historical narratives revolve around modernity and its implications. Modernity unifies past conditions and present realities. History needs diverse narratives to be explained in a certain context. In cinema, movements towards these goals concern a certain filmic "reality", but despite - or because of - this, the ambivalence of the situation finds its aesthetics in another way. ${ }^{17}$ In Jancsó's visual narrative, the perspective of a single moment, dislocates the next move, but the lines linking the viewpoints of the characters are usually in control, linking together the performance and the camerawork. In other words, the movements of the camera gain their controllability through this interaction between the performers and the camera.

His films give spirit and vigour to audio-visual ideas, because his cinema needs the painterly atmosphere to be fully alive with movement and activity. He uses conventions and techniques, which are specific to film, but, at the same time, form a meaningful continuity between different functions, and traditions of art. It gives certain autonomy to his works, since they are situated under the wings of these historical relations between painting, photography and cinema, trying to figure out how cinema evolved in relation to these phenomena, as well as trying to discover film's hidden links and influences. The questions of time and space come forward in this display of moments, affecting the spectator's situation in the narrative. Miklós Jancsó's experimentalism embraces different practices of filmmaking that are unified through a fascination with cinematographic representation, perception and the expressive, imaginary qualities of the world me- 
diated and transformed in visual culture. Film's historical antecedents, painting and photography, are at stake here.

\section{Notes}

1 Landscape here is understood as (1) a picture of natural scenery, (2) a portion of land that the eye can see in one glance, and (3) a mental picture, a human internal "landscape".

2 See Budd, Malcolm (1993) How Pictures Look, in D. Knowles and J. Skorupski (eds.) Virtue and Taste. Oxford: Blackwell, 154-75. Reprinted in Peter Lamarque and Stein Haugoin Olsen (2004) (eds.) Aesthetics and the Philosophy of Art: The Analytic Tradition. London, Blackwell, 390.

3 See, for example, Anderson, John R. (1976) Language, Memory and Thought. Hillsdale: Lawrence Erlbaum; Barthes, Roland (1991) The Responsibility of Forms: Critical Essays on Music, Art and Representation, translated by Richard Howard. Berkeley, University of California Press; Bíro, Yvette (2008) Turbulence and Flow in Film: The Rhythmic Design. Bloomington, Indiana University Press; Frayling, Christopher (1993) Research in Art and Design. London, Royal College of Art; Gray, Carole and Julian Malins (2004) Visualizing Research: a guide to the research process in art and design. Aldershot, Ashgate; Huyssen, Andreas (1995) Twilight Memories: Marking Time in a Culture of Amnesia. London and New York, Routledge; Flusser, Vilém (2005) Towards a Philosophy of Photography. London, Reaktion Books; Carroll, Noël (1996) Theorizing the Moving Image. Cambridge, Cambridge University Press; Bolt, Barbara (2004) Art Beyond Representation: the performative power of the image. London, I. B. Tauris.

4 See, for example, Bruno, Giuliana (2002) Atlas of Emotion: Journeys in Art, Architecture and Film. New York: Verso; Burnett, Ron (2005) Cultures of Vision. Bloomington and Indianapolis, Indiana University Press; Sturken, Marita and Lisa Cartwright (2001) Practices of Looking: An Introduction to Visual Culture. Oxford, Oxford University Press; Valkola, Jarmo (2016) Pictorialism in Cinema: Creating New Narrative Challenges. Newcastle upon Tyne, Cambridge Scholars Publishing.

5 Ferro, Mark (1988) Cinema and History. Detroit, MI, Wayne State University Press.

6 See about metafilmic strategies, for example, Lipovetsky, Gilles and Jean Serroy (2007) L'écran global. Culture-médias et cinéma à l'âge hypermoderne. Paris, Editions Seuil.

7 See, for example, Ihde, Don (1979) Experimental Phenomenology: An Introduction. New York, Paragon Books; Merleau-Ponty, Maurice (1945) Phénomenologie de la perception. Paris, Librairie Gallimard.

8 See, for instance, Wahlberg, Malin (2008) Documentary Time: Film and Phenomenology. Minneapolis, University of Minnesota Press.

9 See Hochberg, Julian (1964) Perception. New Jersey, Prentice-Hall Inc.

10 Eldridge, Richard (3003) An Introduction to the Philosophy of Art. Cambridge, Cambridge University Press.

11 See Ricoeur, Paul (1984) Time and Narrative, Volume I, trans. Kathleen Blaney and David Pellauer. Chicago III, University of Chicago Press.

12 Petrie, Graham (1998) Red Psalm. London, Anthony Rowe, FB.

13 Thompson, Kristin \& David Bordwell (2003) Film History: An Introduction, (2 ${ }^{\text {nd }}$ edition). London, McGraw Hill.

14 Durgnat, Raymond (2003) "Psaume Rouge”, in Feigelson, Kristian and Jarmo Valkola (eds.) Cinéma hongrois, le temps et l'histoire. Théorème n:o 7. Paris, Presses Sorbonne Nouvelle. 
15 See Valkola, Jarmo (2017) Cognition and Visuality: Analysing Functions of Artistic Modelling. Saarbrücken, LAP Lambert Academic Publishing.

16 See Sobchack, Vivian (1995) "Phenomenology and the Film Experience", in Linda Williams (ed.), Viewing Positions: Ways of Seeing Film. New Brunswick, Rutgers University Press.

17 See, for instance, Rosenstone, Robert, A. (1995) Visions of the Past: The Challenge of Film to Our Idea of History. Cambridge, Harvard University Press; Stubbs, Jonathan (2013) Historical Film: A Critical Introduction. London, Bloomsbury. 